\title{
Protein Artemis
}

National Cancer Institute

\section{Source}

National Cancer Institute. Protein Artemis. NCl Thesaurus. Code C90042.

Protein artemis (692 aa, $\sim 78 \mathrm{kDa}$ ) is encoded by the human DCLRE1C gene. This protein is involved in nuclease activity that modulates both DNA repair and $V(D)$ J recombination. 